\title{
USING A VIRTUAL DUMMY TO SIMULATE VIBRATION DOSE VALUE FOR DIFFERENT CAR OCCUPANTS
}

\author{
E. Pennestrì, R. Stefanelli, P.P. Valentini, L. Vita \\ Department of Mechanical Engineering \\ University of Rome Tor Vergata \\ Via del Politecnico 1, 00133 Rome (Italy) \\ Email: vita@ing.uniroma2.it \\ Tel. +390672597136 Fax. +39062021351
}

\begin{abstract}
The comfort assessment for car occupants is not an easy task to achieve. It is a matter of personal perceiving, thus a solution which may seem comfortable to one could be not to another. Moreover it is a field which requires knowledge both from science and medicine. The vibrational comfort analysis is the topic of this paper. There are different international standards to define the vibrational comfort through computed indices. In particular the British Standard BS 6841 [1] introduces the Vibration Dose Value (VDV). The main idea which lies behind the VDV is to estimate the whole body vibration. In fact the standard suggests the main locations for acceleration measurement (feet, seat and back) and their direction axes. The overall number of acquisitions is twelve. A numerical code for the vibrational comfort analysis of car occupants, estimating the VDV for each of them, has been developed. The code, named DAViD, is based on a multibody approach [2]. It has been validated by means of experimental tests [3,4]. In this paper the influence of the anthropometric features (height and weight) and the inclination of the backrest on the VDV has been investigated. The code is an useful tool for predicting at the seat design level the vibrational discomfort.
\end{abstract}

\section{NOMENCLATURE}

$a_{r . m . s .} \quad$ Acceleration root mean square.

$a_{w} \quad$ Frequency-weighted acceleration time-history.

$e V D V \quad$ Estimated vibration dose value.

$h \quad$ Height of the subject.

$\begin{array}{ll}{ }_{\text {perc }} & \text { Height percentile. } \\ T & \text { Period of time of vibration exposure. } \\ t_{\lim } & \text { limit exposure time. } \\ V D V & \text { Vibration dose value. } \\ W_{b} W_{c} W_{d} W_{e} & \text { Weighting factors according to BS } 6841 \\ w_{p} & \text { Weight of the subject. } \\ { }^{2} & \text { Weight percentile. }\end{array}$

\section{INTRODUCTION}

The vibrational comfort analysis of car occupants grew in importance in the last decade. This is due to two main reasons. The first one is to reduce the negative effects on health of the whole body vibration; the second is to improve the comfort perceived by car occupants for market purposes. It is not easy to define all the problems involved in the evaluation of the vibration dose perceived by car occupants. Many authors in their works tried to point out the main features of this complex research $[7,8,9,10,11,12,13,14,15]$.

This research unit is involved in the vibration comfort analysis of car occupants $[3,4,5,6]$. The code developed, named DAViD (Dynamic Automotive Virtual Dummy), is based on a multibody approach. By running the code it is possible to obtain the Fast Fourier Transform (FFT) of the accelerations of all the main body segments and the Vibration Dose Value (VDV) for each of them and then for the whole body. The VDV has been computed according to the British Standard BS 6841 . Numerical simulations concerning the influence of

\footnotetext{
* Address all correspondence to this author.
} 
anthropometric features and of driver posture on the value of this parameter, are herein presented. A comparison between the vibration perceived by the driver and by the passengers is also reported. The results have been validated by experimental tests presented in [17].

\section{THE EFFECTS OF VIBRATIONS ON HUMAN BODY}

When a vibration source is placed into contact with human body the so called whole body vibration (WBV) takes place. An example of vibration source is car environment. In this contest the frequency range of interest for studying the effects of WBV is $0.5-50 \mathrm{~Hz}$. For example seats have low frequencies of resonance, thus they amplify the effects of vibration for frequencies lower than $10 \mathrm{~Hz}$ [1]. It is important to consider also the resonance frequencies of each body segment. In fact dangerous effects for health could arise if the WBV is near to these resonance frequencies. The effects of vibration on the skeletal muscle apparatus have been studied varying the frequency and the amplitude of vibration. The results revealed that the most dangerous vibrations are those below $6 \mathrm{~Hz}$. The first resonance frequency for a human body seated in a car is about $5 \mathrm{~Hz}$, the second one is about $8 \mathrm{~Hz}$.

The effects of vibrations on man could be classified according to level of dangerousness:

- tiredness;

- decrease of efficiency and attention;

- damage.

For a complete assessment of the vibration absorbed by human body three main aspects need to be considered: the amplitude, the frequency and the duration of the excitation. For example a vibration with small amplitude but long duration could be equivalent to one with greater amplitude and shorter duration. In Table 1 are summarized the main effects of vibrations on human body.

\section{Table 1. EFFECTS OF VIBRATIONS ON HUMAN BODY}

\begin{tabular}{|c|l|}
\hline $\begin{array}{c}\text { Frequency } \\
{[\mathbf{H z}]}\end{array}$ & \multicolumn{1}{c|}{ Effect } \\
\hline $1-2$ & Dyspnoea (longitudinal vibration) \\
\hline 2 & Head resonance for horizontal vibration \\
\hline $1-3$ & Max sensitiveness for respiratory apparatus \\
\hline $2-3$ & Resonance of shoulder - head \\
\hline $2-6$ & Resonance of the whole seated body \\
\hline $3-4$ & Abdominal problems \\
\hline $4-6$ & Resonance of thorax and abdomen \\
\hline $4-10$ & Progressive decrease of visual acuity \\
\hline $4-10$ & Changing in voice \\
\hline $6-10$ & $\begin{array}{l}\text { Changing in arterial pressure, cardiac } \\
\text { frequency and oxygen consumption }\end{array}$ \\
\hline $10-12$ & Sleepiness \\
\hline $13-15$ & Resonance of pharynx \\
\hline $13-20$ & Head resonance and augment of muscular tone \\
\hline $20-30$ & $\begin{array}{l}\text { Max resonance of whole body with decrease } \\
\text { of visual acuity }\end{array}$ \\
\hline $30-40$ & Vascular problems \\
\hline $30-90$ & Resonance of ocular globes \\
\hline $40-600$ & Resonance of skull \\
\hline $100-200$ & Resonance of jaw \\
\hline & \\
\hline
\end{tabular}

In the mentioned field of interest, the effects of vibrations are mostly due to the exposure time. Often the induced vibrations, even if their amplitude could reach high values, are not rapidly injurious. Thus the annoyance or the kinetosis are the most common effects, while only prolonged exposure to vibration could induce visible damages. In Figure 1 an example of acceleration acquired at driver seat is shown.

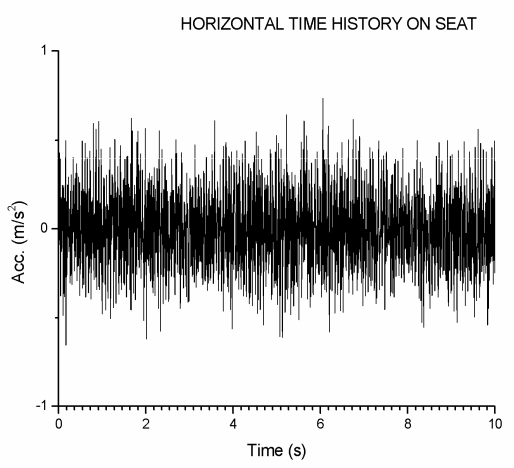

Figure 1. EXPERIMENTAL ACCELERATION TIME HISTORY AT DRIVER SEAT

\section{THE VIBRATION DOSE VALUE}

The vibrational comfort is deeply correlated to disturbs of perceptions, tiredness and annoyance while driving a car. Thus the importance of predicting the discomfort perceived by car occupants in order to prevent, at least, car accidents. Moreover the comfort perception is quite subjective and it is not easy to generalize. There are several international standards which concern comfort assessment. According to the authors opinion, the most comprehensive is the British Standard BS 6841. Mainly because:

- It takes into account the body vibration of several body segments to estimate the discomfort caused by whole body vibration: along the three translational directions of feet; along the three translational directions of torso; along the three translational directions and about the three rotational axes of pelvis (Figure 2).

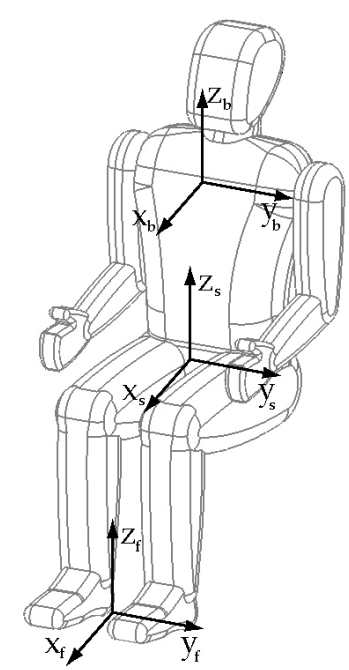

Figure 2. MEASUREMENT POINTS AND AXES LOCATION ACCORDING TO BS 6841 
- It is the first norm which defines how to implement the filtering frequencies by means of both analogical and digital methods. It defines four frequency weightings as reported in Table 2 .

\begin{tabular}{|c|c|c|c|}
\hline & Axes $^{1}$ & Frequency range $[\mathrm{Hz}]$ & Value \\
\hline \multirow{4}{*}{$W_{b}$} & \multirow{4}{*}{$\begin{array}{l}y_{s} \\
x_{f} \\
y_{f} \\
z_{f}\end{array}$} & $0.5<f<2.0$ & $W(f)=0.4$ \\
\hline & & $2.0<f<5.0$ & $W(f)={ }^{f} / 5.0$ \\
\hline & & $5.0<f<16.0$ & $W(f)=1.0$ \\
\hline & & $16.0<f<80.0$ & $W(f)=16.0 / f$ \\
\hline \multirow{2}{*}{$W_{c}$} & \multirow{2}{*}{$x_{b}$} & $0.5<f<8.0$ & $W(f)=1.0$ \\
\hline & & $8.0<f<80.0$ & $W(f)=8.0 / f$ \\
\hline \multirow[b]{2}{*}{$W_{d}$} & \multirow{2}{*}{$\begin{array}{l}y_{b} \\
z_{b} \\
x_{s} \\
z_{s}\end{array}$} & $0.5<f<2.0$ & $W(f)=1.0$ \\
\hline & & $2.0<f<80.0$ & $W(f)=2.0 / f$ \\
\hline \multirow{2}{*}{$W_{e}$} & \multirow{2}{*}{$\begin{array}{l}x_{s} \\
y_{s} \\
z_{s}\end{array}$} & $0.5<f<1.0$ & $W(f)=1.0$ \\
\hline & & $1.0<f<20.0$ & $W(f)=1.0 / f$ \\
\hline
\end{tabular}

- Three aspects of vibration are fundamentals: the exposure time, the amplitude and the frequency. The BS 6841 takes into account all these aspects in a unique parameter: the Vibration Dose Value (VDV). In particular the VDV handles also the effects of unpredictable shocks and it could be used for any exposure time (even for few seconds).

In accordance with Griffin [1] the VDV could be evaluated as follow:

$$
V D V=\left(\int_{0}^{T} a_{w}^{4}(t) d t\right)^{\frac{1}{4}} \quad\left[\mathrm{~m} \mathrm{~s}^{-1.75}\right]
$$

where $a_{w}(t)$ is a frequency-weighted acceleration time-history and $T$ is the period of time over which vibration is measured. If the acceleration time history is not available but its r.m.s. is known, the estimated value of vibration dose could be calculated (eVDV):

$$
e V D V=\left[\left(1.4 \cdot a_{r . m . s .}\right)^{4} \cdot T\right]^{1 / 4} \text {. }
$$

This expression does not work properly for a crest factor greater than 6.0. The standard sets in $15 \mathrm{~m} \cdot \mathrm{s}^{-1.75}$ the VDV threshold value, above which it is possible to incur in health disease. In Figure 3 is shown the computational scheme proposed by the BS 6841 .

The expression (1) allows to define the vibration dose value for a single body segment. Thus the overall VDV is obtained following these steps:

1. Acquire the accelerations for each body segment;
2. Transform the signal acquired from time domain into frequency domain;

3. Apply the weighting factors according to Table 2;

4. Multiply the result of previous step for the axis multiplying factor (see Figure 4);

5. Evaluate the VDV for each body segment, and finally the overall VDV as:

$$
V D V_{\text {overall }}=\left(\sum_{\text {channel }} V D V^{4}\right)^{1 / 4} .
$$

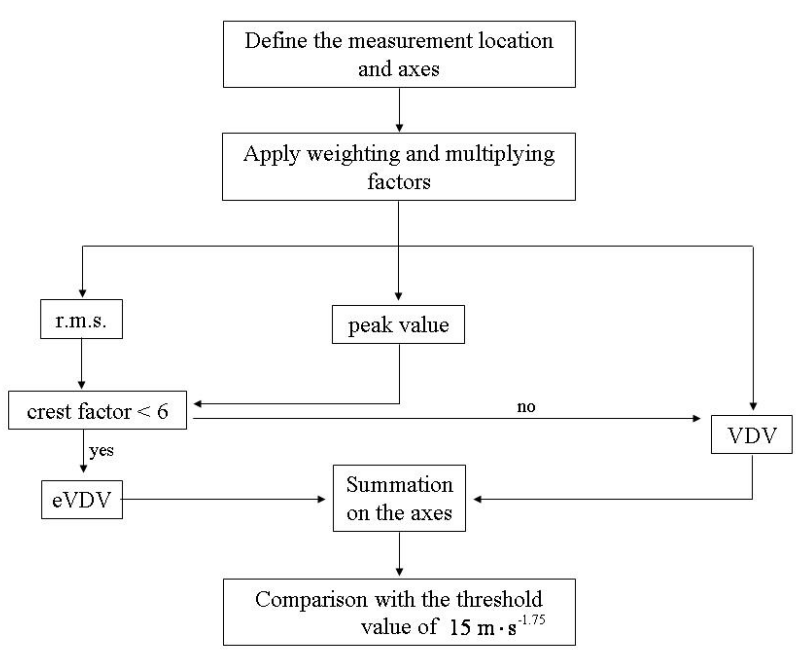

Figure 3. COMPUTATIONAL SCHEME

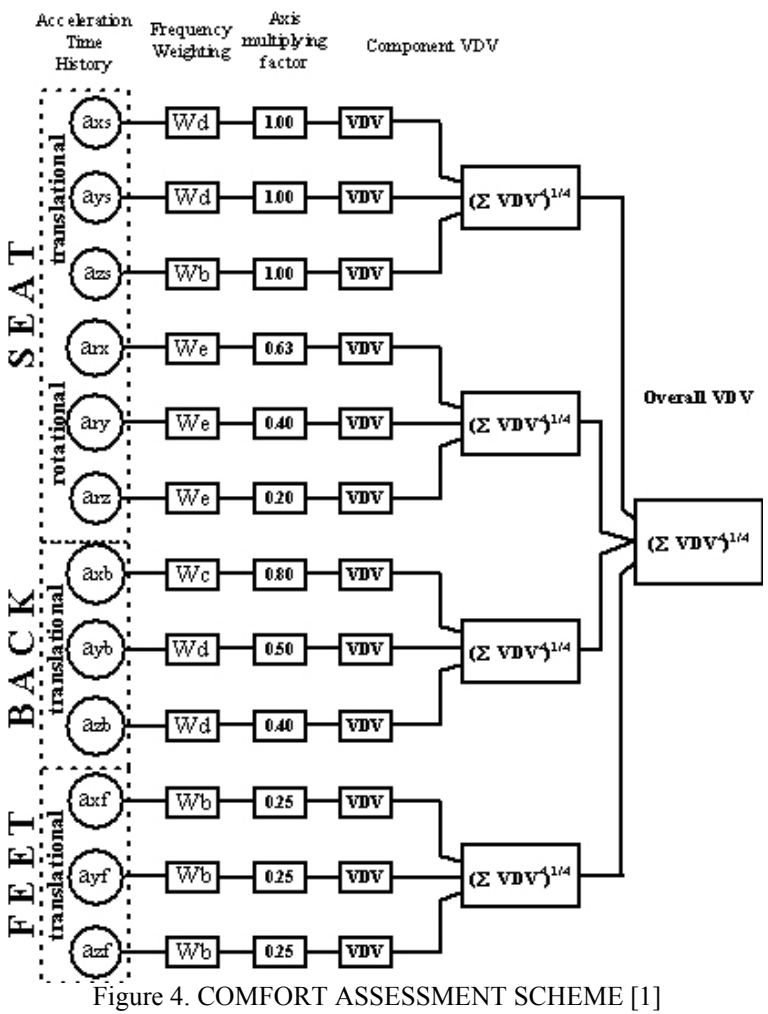

${ }^{1}$ With reference to Figure 2. 
According to Mansfield [16] it is also possible to define the limit exposure time to reach the threshold value as:

$$
t_{\lim }=\left(\frac{15}{V D V}\right)^{4} \cdot t \text {. }
$$

\section{THE VIRTUAL DUMMY}

The proposed human body model is made up of twelve rigid bodies linked together by means of eleven kinematic pairs. Moreover three viscoelastic elements have been modelled to represent the muscular elasticity and the articular limits of elbow and knee articulations and torso ${ }^{2}$. The whole model of the dummy is completely scalable according to the height and weight percentile chosen. In particular two variational laws for each of the mentioned percentile have been deduced. In the range of $20^{\text {th }}-80^{\text {th }}$ percentile, the height $h$ could be evaluated as

$$
h=1.715+\frac{11}{6000}\left(h_{\text {perc }}-20\right) \quad[\mathrm{m}] .
$$

In the same manner the weight $w$ could be evaluated as follow in the range of $5^{\text {th }}-95^{\text {th }}$ percentile:

$$
w=64.21+\frac{22}{90}\left(w_{\text {perc }}-5\right) \quad[\mathrm{kg}] .
$$

The $50^{\text {th }}$ percentile both for height and for weight represents a man of $75 \mathrm{~kg}$ and $1.77 \mathrm{~m}$.

Once known the anthropometric features of the whole body it is possible to properly define the geometric and inertial features of each body segment (Figure 5).

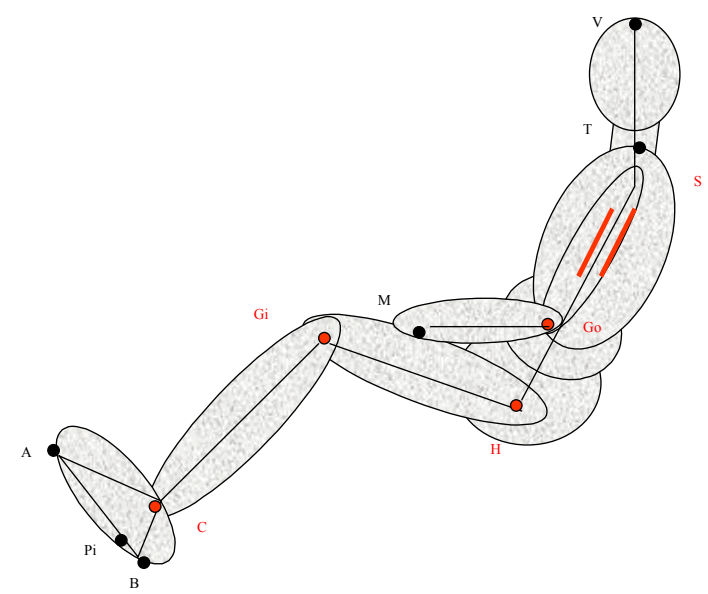

Figure 5. BODY SEGMENTS AND REFERENCE POINTS

\section{NUMERICAL SIMULATIONS}

In this section several simulation scenarios are reported. In particular the overall VDV has been evaluated for different backrest inclinations and different human kinds (varying the height and weight percentile). The code used is the in house developed DAViD $[3,4]$. This code is able to manage multi inputs in terms of acceleration, velocity and position time histories. The output files for each rigid body of the system under investigation are position, velocity and acceleration of the centre of mass. Moreover the code evaluates the overall VDV, in accordance with the BS 6841, and the time exposure

\footnotetext{
${ }^{2}$ For more details of the virtual dummy multibody model refer to $[3,4]$
}

for each car occupant. In the simulations scenarios herein reported the multi inputs applied represent an highway path at the constant speed of $100 \mathrm{~km} / \mathrm{h}$. The first simulation refers to the driver with the height percentile kept constant at 50, backrest inclination equal to $23^{\circ}$ (which is considered the reference configuration) while the weight percentile has been varied. In particular the weight of the subject varies from 64.21 $\mathrm{kg}$ to $86.21 \mathrm{~kg}$. In Figures 6,7 and 8 the single VDV of pelvis, torso and feet respectively are reported.

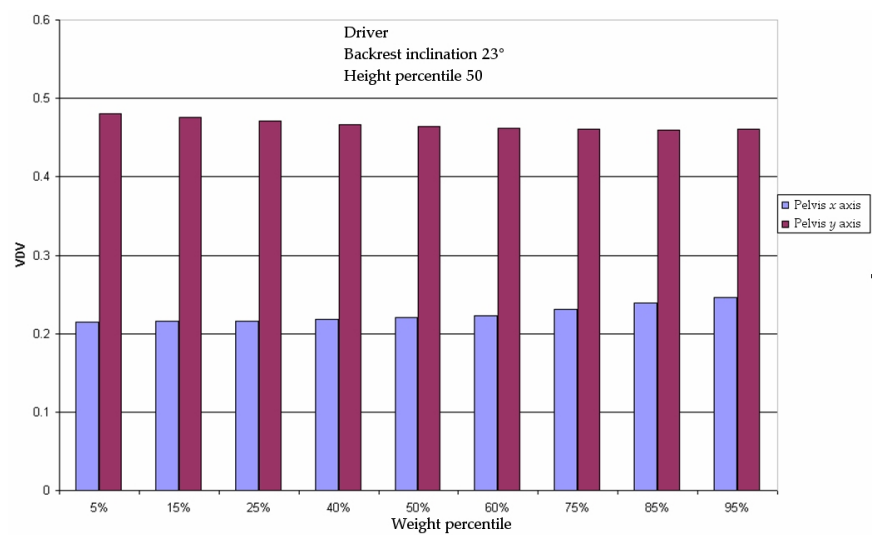

Figure 6. PELVIS VDV WITH VARIABLE WEIGHT PERCENTILE

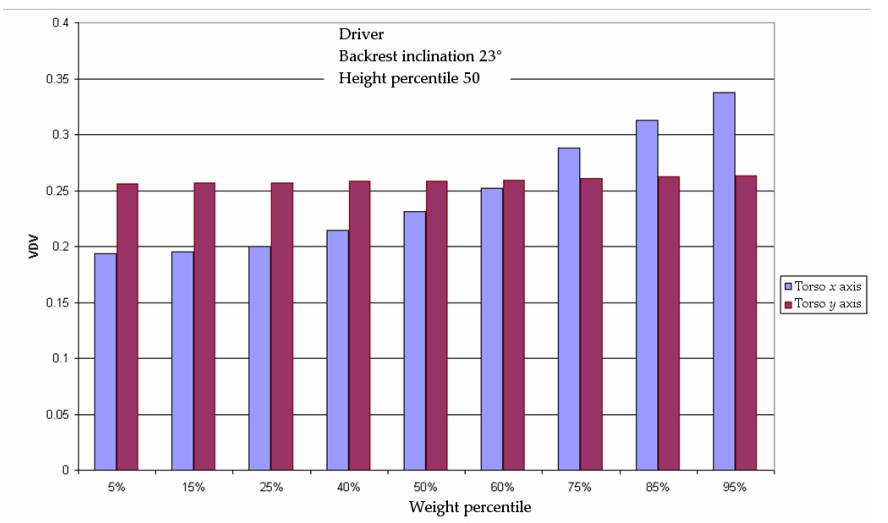

Figure 7. TORSO VDV WITH VARIABLE WEIGHT PERCENTILE

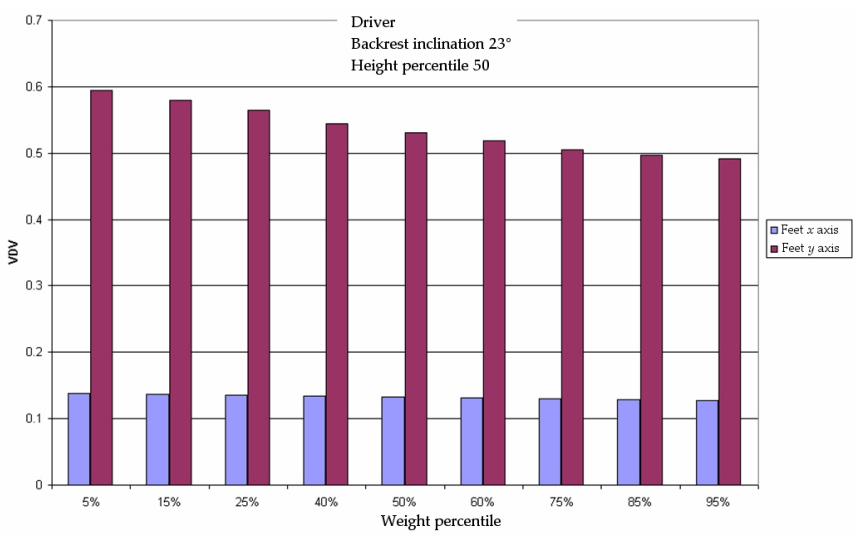

Figure 8. FEET VDV WITH VARIABLE WEIGHT PERCENTILE

Considering torso and pelvis the VDV along $y$ axis is quite constant for both, instead along $x$ axis the VDV increases its value as the weight percentile increases. Considering feet the behaviour is right the opposite. The overall VDV is shown in 
Figure 9. While the weight percentile increases, the overall VDV decreases. The maximum value computed is 0.658 , which is quite far from the threshold value.

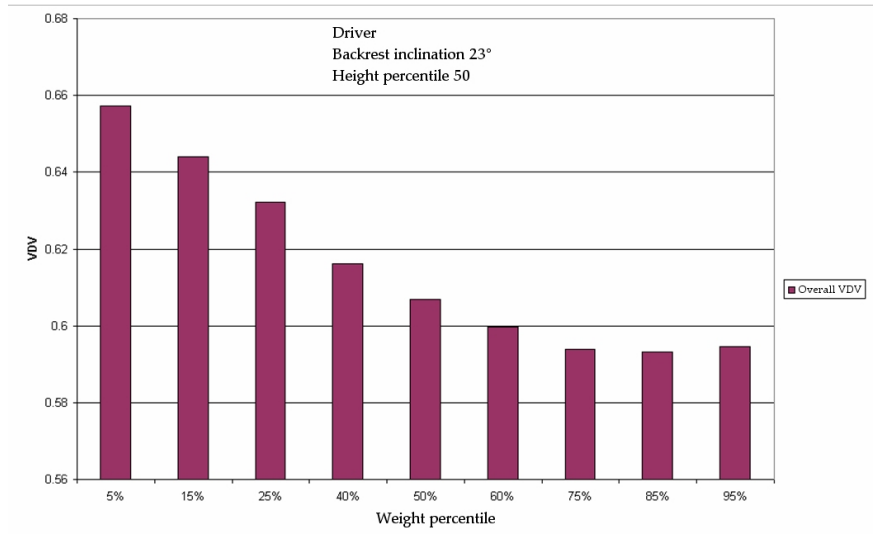

Figure 9. OVERALL VDV WITH VARIABLE WEIGHT PERCENTILE

For this second simulation all the parameters are the same as the previous one, apart from the weight percentile which now assumes a constant value of 50 , while the height percentile is variable. In particular the height of the subject varies from 1.71 $\mathrm{m}$ to $1.82 \mathrm{~m}$. In Figures 10,11 and 12 the VDV of pelvis, torso and feet respectively are reported.

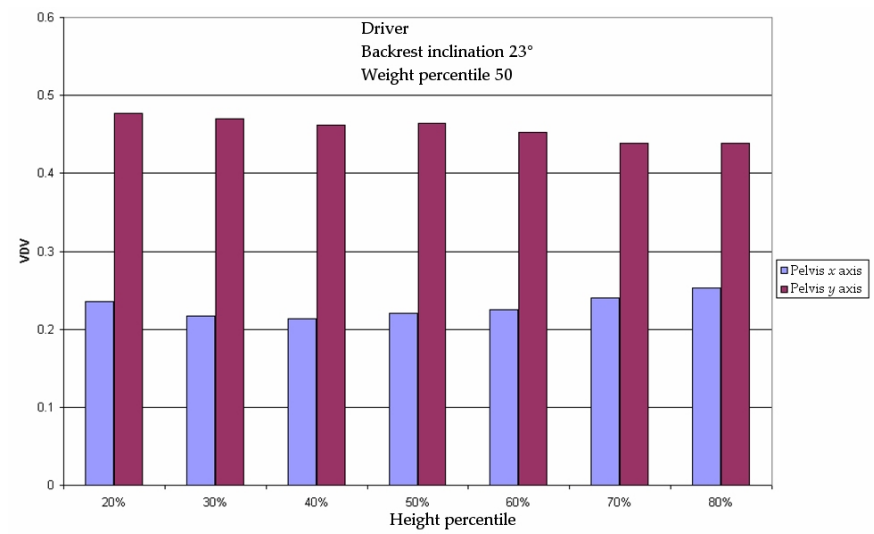

Figure 10. PELVIS VDV WITH VARIABLE HEIGHT PERCENTILE

Considering pelvis, the VDV along $y$ direction is insensitive to variation of the height percentile. Along $x$ direction, instead, it increases its value. Considering torso, the VDV along $x$ axis has minimum values in the range of $40^{\text {th }}-50^{\text {th }}$ height percentile. The VDV of feet is instead completely insensitive to variation of height percentile in both directions. The overall VDV, reported in Figure 13, shows an absolute maximum in correspondence of $h_{\text {perc }}=20$, and a local maximum for $h_{\text {perc }}=50$.

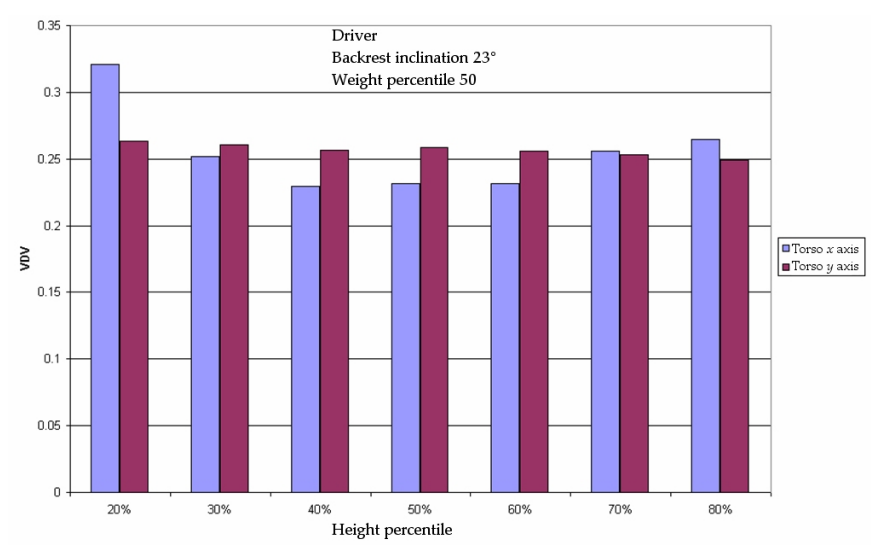

Figure 11. TORSO VDV WITH VARIABLE HEIGHT PERCENTILE

For both the simulations the limit exposure time is 24 hours. This is reasonable considering that the track is an highway and the velocity is kept constant.

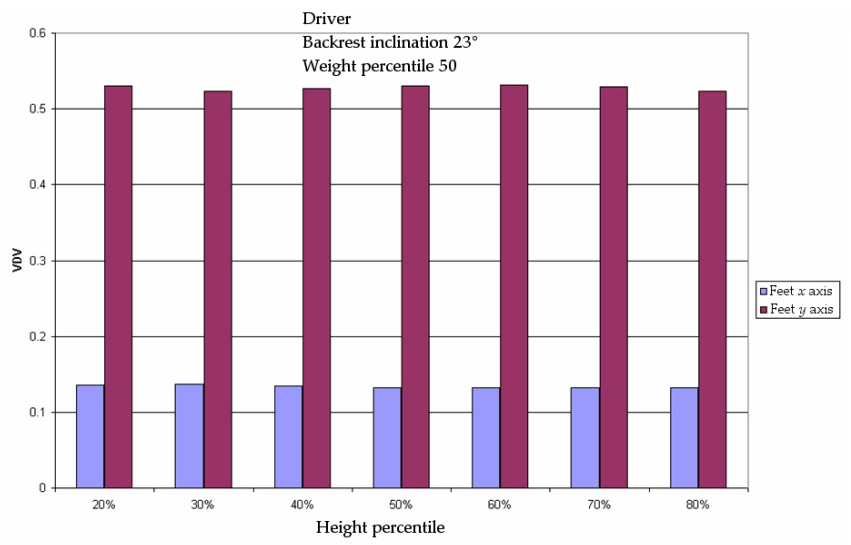

Figure 12. FEET VDV WITH VARIABLE HEIGHT PERCENTILE

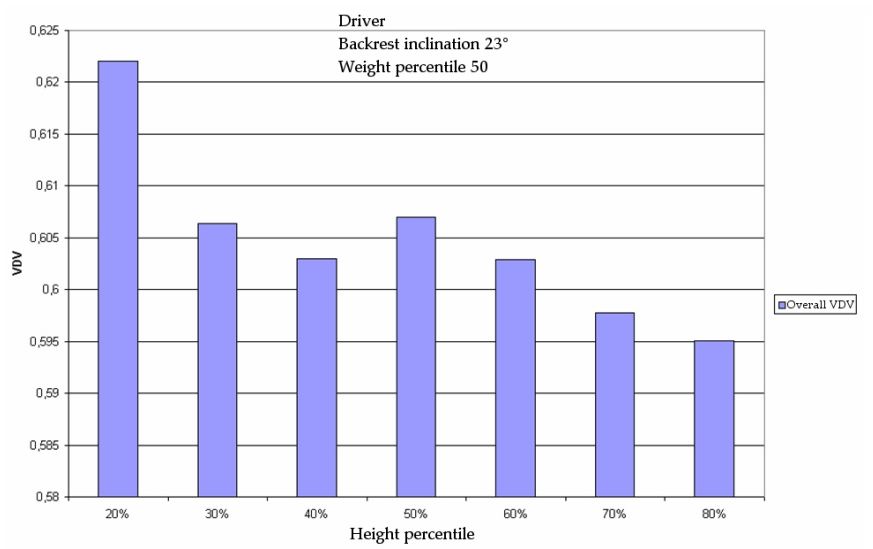

Figure 13. OVERALL VDV WITH VARIABLE HEIGHT PERCENTILE

The influence of backrest inclination on the vibration perceived has been also investigated. The anthropometrical features of the driver have been kept constant (height $1.77 \mathrm{~m}$, weight $75 \mathrm{~kg}$ ). The inclination of the backrest has been measured from the 
vertical and its range has been chosen from $13^{\circ}$ to $25^{\circ}$. Figures 14 and 15 represent the VDV of pelvis and torso for this simulation. It can be observed that the VDV of these body segments increases its value in correspondence of positions nearest to vertical. The torso VDV is also sensitive to configuration of the backrest more tilted (Figure 14).

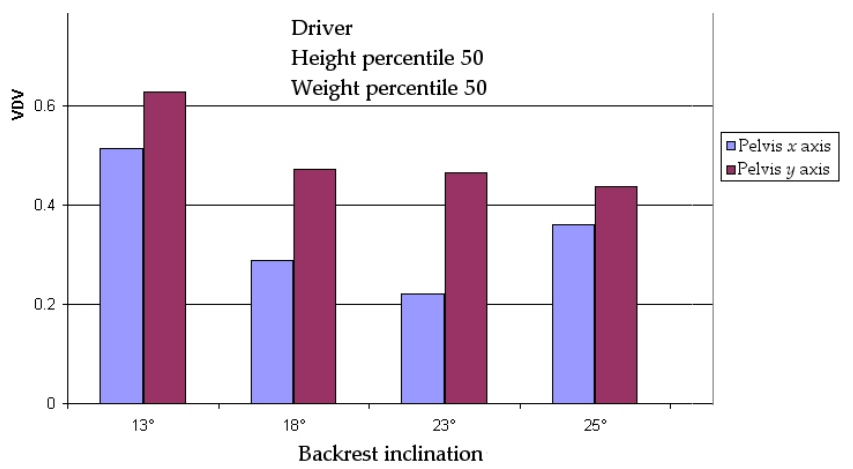

Figure 14. PELVIS VDV WITH VARIABLE BACKREST INCLINATION

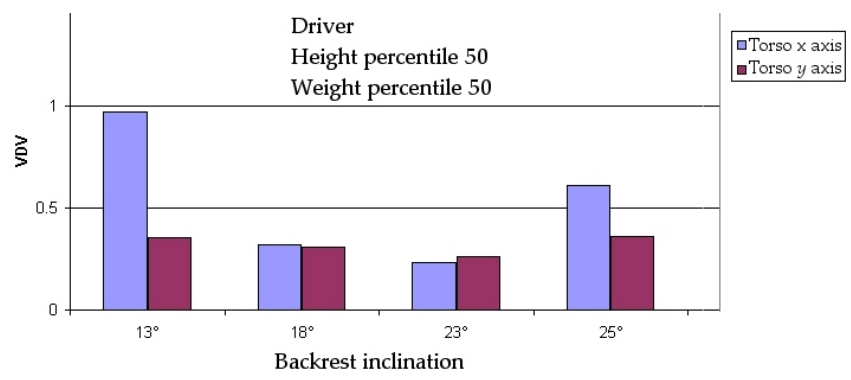

Figure 15. TORSO VDV WITH VARIABLE BACKREST INCLINATION

The overall VDV (Figure 16) attains its lowest value in correspondence of a backrest inclination of $23^{\circ}$, which represents the configuration of right posture while driving a car.

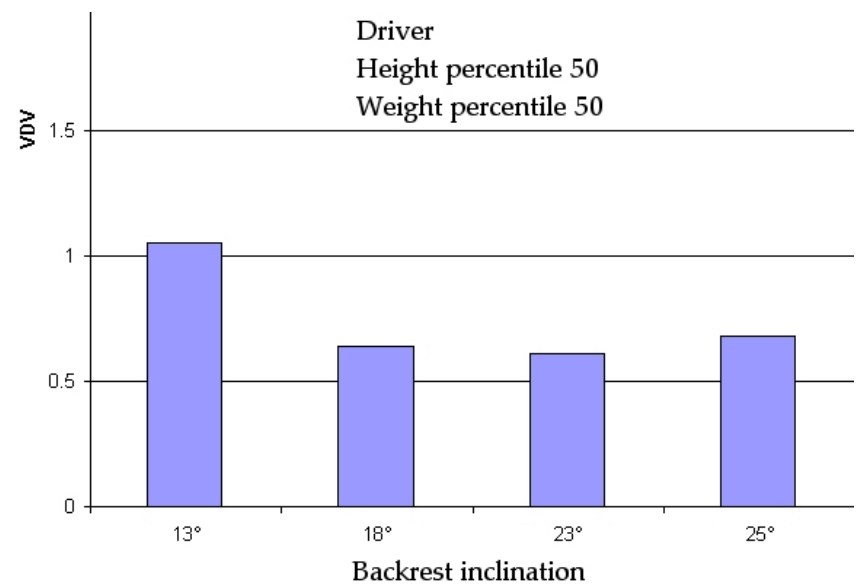

Figure 16. OVERALL VDV WITH VARIABLE BACKREST INCLINATION

The last simulation concerns the comparison between the VDV of the driver and the passenger. Both of them belong to the $50^{\text {th }}$ percentile category. The main difference in the posture of the subjects is the position of hands. The driver has his hands on the steering wheel, while the passenger has been supposed to have his hands on his thighs. This leads to VDV values for each passenger body segment, and as a consequence for the overall VDV, higher than the ones of the driver (Figure 17). This behaviour could be explained considering that the body stiffens by exerting forces on the steering wheel.

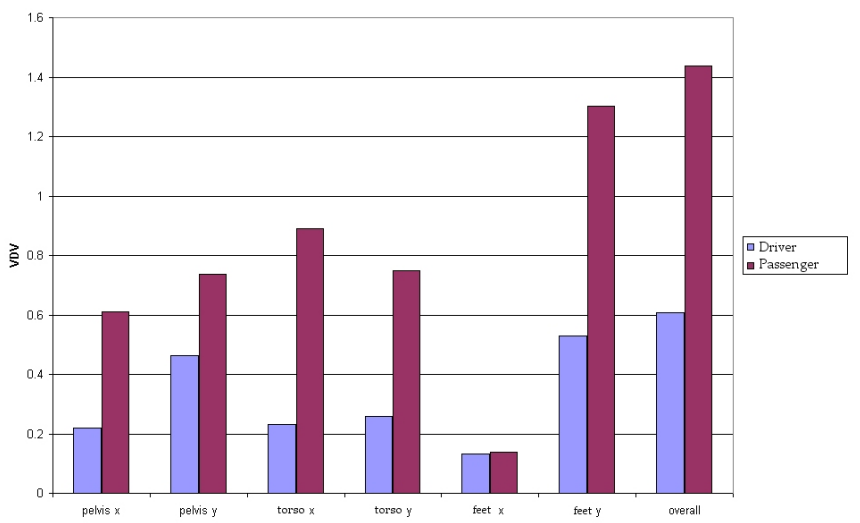

Figure 17. COMPARISON BETWEEN DRIVER AND PASSENGER VDV

Moreover a last comparison has been herein presented. The results of $D A V i D$ code have been compared to the ones presented by Griffin and Lewis in [17]. They refer to a driver in a car on highway at the constant speed of $100 \mathrm{~km} / \mathrm{h}$. The inputs have been sampled at $512 \mathrm{~Hz}$ for 60 seconds. In Figure 18 the comparison is shown.

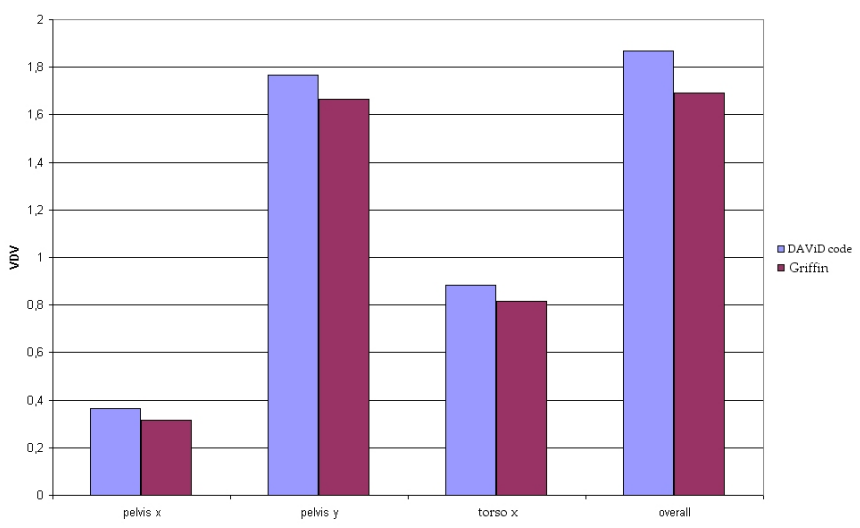

Figure 18. COMPARISON BETWEEN DAViD AND EXPERIMENTAL DATA

The VDV evaluated by means of the code is in good agreement with the experimental one. The higher values obtained by means of the simulation are to advantage of safety.

\section{CONCLUSIONS}

Numerical simulations concerning the evaluation of the vibration dose value for different drivers have been proposed. The model foresees the following behaviours:

- An increase of weight of the subject corresponds a decrease of the overall VDV. The torso VDV in longitudinal direction is the most sensitive to weight variations.

- An increase of height of the subject corresponds to decrease of the overall VDV. The torso VDV in 
vertical direction is quite insensitive to height variations.

- The passenger has always VDV values greater than the driver.

The code implemented reveals as an useful tool for the prediction of perceived vibration and for preventing health problems while driving a car.

\section{REFERENCES}

[1] M.J. Griffin, Handbook of Human Vibration, Academic Press, 1990

[2] E.J. Haug, Computer Aided Kinematics and Dynamics of Mechanical Systems, Allyn and Bacon, vol. I, pp.48-104, 1989

[3] P. P. Valentini, L. Vita, DAViD - A Multibody Code to Simulate a Dynamic Virtual Dummy for Vibrational Comfort Analysis of Car Occupants, NATO ASI Workshop Praga, 2002

[4] P. P. Valentini, L. Vita, DAViD - A multibody virtual dummy for vibration comfort analysis of car occupants, W. Schielen and M. Valasek eds., Virtual Nonlinear Multibody Systems, Kluwer Academic Publishers, pp.253-262, 2003

[5] P. Campanile, L. Celiberti, F. Barizzone, A. Rosati, E. Pennestrì, P.P. Valentini, Implementazione Mediante Tecniche Multibody di un Modello per la Simulazione delle Dinamiche Vibrazionali del Sistema Uomo-Sedile, Proceedings of XV AIMETA Congress of Theorical and Applied Mechanics, Taormina (ME) 26-29 settembre 2001 (in italian)

[6] P. Campanile, L. Celiberti, F. Barizzone, A. Rosati, E. Pennestrì, P.P. Valentini, The Development of a Virtual Dummy for the Vibrational Comfort Analysis of Car Drivers, 6th U.S. National Congress on Computational Mechanics, Dearborn, Michigan, USA, 2001

[7] F.M.L Amirouche, M. Xie, A. Patwardhan, Optimization of the contact damping and stiffness coefficients to minimize human body vibration, Journal of Biomechanical engineering, vol 116, 1994

[8] C.H. Lewis, Evaluating the vibration isolation of soft seats using an active anthropodynamic dummy, 35th
United Kingdom Group Meeting on Human Responses to Vibration, ISRV, Southampton University, England, 2000

[9] Lin Wei, M.J. Griffin, Effect of subject weight on predictions of seat cushion transmissibility, 35th United Kingdom Group Meeting on Human Responses to Vibration, ISRV, Southampton University, England, 2000

[10] Xuting Wu, S. Rakheia, P.E. Boileau, Study of Human-Seat interactions for Dynamic Seating Comfort Analysis, Society of Automotive Engineers, 1999

[11] Se-Jin Park, Young-Shin Lee, Toon-Eui Nahm, Jung Woo Lee, Jin-Sun Kim, Seating Physical Characteristics and Subjective Comfort: Design Considerations, Society of Automotive Engineers, Inc., 1988

[12] P. Kirchknopf, et al., Development of a multibody calculation model for the passenger/seat system based on experimental results, ATA paper n.01A 1085

[13] Vibration Injury Network, Review of Methods for Evaluating Human Exposure to Whole-body Vibration, Appendix W4A to final report, 2001

[14] P.G. Bedewi, N.E. Bedewi, Modelling of Occupant Biomechanics with Emphasis on the Analysis of Lower Extremity Injuries, FHWA/NHTSA National Crush Analysis Center, The George Washington University, Virginia USA

[15] C.M. Harris, Shock Vibration Handbook, McGraw Hill, 1988

[16] N.J. Mansfield, Localized vibration at the Automotive Seat-Person Interface, the 2001 International Congress and Exhibition on Noise Control Engineering, 2001

[17] C.H. Lewis, M.J. Griffin, A Comparison of Evaluations and Assessment Obtained Using Alternative Standards for Predicting the Hazards of Whole-body Vibration and Repeated Shocks, Journal of Sound and Vibration, vol. 215, pp. 915-926, 1998 